\title{
Understanding terminology of delirium and long-term cognitive impairment in critically ill patients
}

\author{
A. Morandi, MD, MPH, Geriatric Consultant ${ }^{\mathrm{a}, \mathrm{b}, \mathrm{c}, *}$, \\ P.P. Pandharipande, MD, MSci, Associate Professor ${ }^{\mathrm{d}}$, \\ J.C. Jackson, PSyD, Assistant Professor ${ }^{\mathrm{e}, \mathrm{f}}$, \\ G. Bellelli, MD, Assistant Professor ${ }^{\mathrm{b}, \mathrm{g}}, \mathrm{M}$. Trabucchi, MD, Professor ${ }^{\mathrm{b}, \mathrm{h}}$, \\ E.W. Ely, MD, MPH, Professor ${ }^{c, f, g, i}$ \\ ${ }^{a}$ Department of Rehabilitation and Aged Care Unit Hospital Ancelle, Cremona, Italy \\ ${ }^{\mathrm{b}}$ Geriatric Research Group, Brescia, Italy \\ ${ }^{\mathrm{c}}$ Center for Quality of Ageing, Vanderbilt Medical School, Nashville, TN, USA \\ ${ }^{\mathrm{d}}$ Anesthesia Service, Department of Veterans Affairs Medical Center, Tennessee Valley Healthcare System, Nashville, TN, USA \\ ${ }^{\mathrm{e}}$ Center for Health Services Research Vanderbilt Medical School, Nashville, TN, USA \\ ${ }^{\mathrm{f}}$ VA Tennessee Valley GRECC, Department of Veterans Affairs Medical Center, Tennessee Valley Healthcare System, Nashville, TN, USA \\ ${ }^{g}$ Department of Health Science, University of Milano-Bicocca, S. Gerardo Hospital, Monza, Italy \\ ${ }^{\mathrm{h}}$ University of Tor Vergata, Rome, Italy \\ ${ }^{\mathrm{i}}$ Division of Allergy, Pulmonary, and Critical Care Medicine, Vanderbilt University, Nashville, TN, USA
}

Keywords:

delirium

long-term cognitive impairment

terminology

critical care
Delirium, an acute brain dysfunction, frequently affects intensive care unit (ICU) patients during the course of a critical illness. Besides the acute morbidities, ICU survivors often experience longterm sequelae in the form of cognitive impairment (LTCI-CI). Though delirium and LTCI-CI are associated with adverse outcomes, little is known on the terminology used to define these acute and chronic co-morbidities. The use of a correct terminology is a key factor to spread the knowledge on clinical conditions. Therefore, we first review the epidemiology, definition of delirium and its related terminology. Second, we report on the epidemiology of LTCI-CI and compare its definition to other forms of cognitive impairments. In particular, we define mild cognitive impairment, dementia and finally postoperative cognitive dysfunction. Future research is needed to interpret the trajectories of LTCI-CI, to differentiate it from neurodegenerative diseases and to provide a formal disease classification.

() 2012 Elsevier Ltd. All rights reserved.

\footnotetext{
* Corresponding author. Rehabilitation and Aged Care Unit Hospital Ancelle, Via Gaspare Aselli 14, 26100 Cremona, Italy. Tel.: +390372 535711 .

E-mail address: morandi.alessandro@gmail.com (A. Morandi).
} 


\section{Introduction}

Every year an increasing number of patients are admitted to intensive care units (ICUs) for the management and treatment of a critical illness. The most recent statistics report that yearly, in the world between 13 and 20 million patients are mechanically ventilated, 15-19 million are admitted to an ICU for the treatment of sepsis and 1.1-5.5 million are treated for an acute lung injury. ${ }^{1}$ The advancements in the medical treatments in the last years have led to a handful number of patients surviving a critical illness. ${ }^{2}$ It has been progressively reported that these patients experience an acute and long-term morbidity in the form of cognitive, functional and emotional impairments along with diminished health-related quality of life., 2,3

Delirium is the most common form of acute brain dysfunction, which affects up to $80 \%$ of critically ill patients during an ICU stay, according to the severity of illness. ${ }^{4-6}$ The occurrence of delirium is also an independent predictor of adverse outcomes such as self-extubation and removal of catheters, ${ }^{7}$ longer hospital stay, ${ }^{8-10}$ increased cost, ${ }^{11}$ higher 6-month and 1-year mortality ${ }^{12-15}$ and long-term cognitive impairment. ${ }^{16-20}$

Indeed, cognitive impairment represents a conspicuous component of the long-term sequelae of ICU survivors. ${ }^{16}$ Different studies have analysed the presence of long-term cognitive impairment after a critical illness (LTCI-CI) at different time points showing neurocognitive impairments at 2 months, ${ }^{21} 3$ months, ${ }^{22,23} 6$ months, ${ }^{24,25} 9$ months, ${ }^{26} 1$ year, ${ }^{22,23,27-29} 2$ years $^{30}$ and 6 years ${ }^{31,32}$ after the hospitalisation for a critical illness. At 1 year, $46-70 \%$ of the patients show signs of $\mathrm{LTCI}-\mathrm{Cl}^{22,23,27-29}$ and, even more relevant, LTCI-CI is present in $25 \%$ of those who survive after 6 years. ${ }^{31}$

Among health-care providers, delirium and LTCI-CI are often unrecognised. ${ }^{25}$ Hopkins et al. ${ }^{30}$ showed that only $12 \%$ of the patients surviving a critical illness and admitted to rehabilitation were evaluated for the presence of cognitive impairments. The reason of this underdetection might be related to barriers in the terminology used to define these cognitive impairments. ${ }^{33}$ We have previously reported that among 13 languages using the Romanic characters, only 54\% use the term 'delirium' to indicate the disorder as defined by the Diagnostic and Statistical Manual of Mental Disorders (DSMIV). ${ }^{34}$ Even with LTCI-CI, there is still an uncertainty on how to define it in comparison to other cognitive impairment entities such as mild cognitive impairment ( $\mathrm{MCI})$, dementia and postoperative cognitive decline (POCD).

Here (1) we first review specific terminology of delirium, and then (2) we compare the definition of LTCI-CI with MCI, dementia and POCD.

\section{Delirium terminology}

Delirium is defined, accordingly to the DSM-IV-TR criteria, ${ }^{34}$ as a clinical condition characterised by (1) a disturbance of consciousness with inattention, accompanied by (2) acute change in cognition (i.e., memory deficits, disorientation, language disturbances and perceptual disturbances) that is not better accounted for by a pre-existing, established or evolving dementia; (3) the disturbance develops over a short period of time (hours to days) with fluctuation over time; and (4) there is an evidence that the disturbance is caused by the direct physiological consequences of a general medical condition. The knowledge and the interest on delirium in critically ill patients have progressively increased over the course of the last few years. ${ }^{33,35}$ Nonetheless, there is still a lack of homogeneity in the use of terminology especially by physicians and health-care personnel who do not specialise in neuropsychiatric disciplines and for different background training and categorisation system. In a previous international survey, ${ }^{33}$ we found that two terms are very consistently used when referring to acute brain dysfunction in critically ill patients: $100 \%$ of the selected languages use the term 'coma' or 'koma' to describe patients unresponsive to verbal and/or physical stimuli, and $100 \%$ use delirium tremens to define delirium due to alcohol withdrawal. Conversely, only $54 \%$ use the term delirium to indicate the disorder as defined by the DSMIV. ${ }^{34}$ Several years ago, Lipowski ${ }^{36}$ called delirium "the Cinderella of American Psychiatry: taken for granted, ignored, and seldom studied." These findings underline the importance of providing further knowledge not just on the general definition of delirium but specifically on the terminology used in the research and clinical settings according to the time course, subtypes and sub-syndromal forms (Fig. 1). 
Overview of the terminology of delirium

Overall definition of delirium:

A clinical condition characterized by (1) a disturbance of consciousness with inattention, accompanied by (2) acute change in cognition (i.e., memory deficits, disorientation, language disturbances and perceptual disturbances) that is not better accounted for by a pre-existing, established or evolving dementia; (3) the disturbance develops over a short period of time (hours to days) with fluctuation over time; (4) there is evidence that the disturbance is caused by the direct physiological consequences of a general medical condition.

\begin{tabular}{l}
$\begin{array}{c}\text { Terminology according } \\
\text { to time course }\end{array}$ \\
\hline - Prevalent delirium \\
Delirium is detected at the time \\
of admission to a clinical setting \\
- Incident delirium \\
delirium newly occurs during \\
the course of a stay in a clinical \\
setting \\
- Persistent delirium \\
delirium symptoms persist over \\
the course of time
\end{tabular}

\begin{tabular}{|c|c|}
\hline $\begin{array}{l}\text { Motoric subtypes } \\
\text { classification }\end{array}$ & Additional definitions \\
\hline $\begin{array}{l}\text { - Hyperactive delirium } \\
\text { is characterized by increased } \\
\text { psycho-motor activity with agitated } \\
\text { behavior } \\
\text { - Hypoactive delirium or "quiet" } \\
\text { delirium } \\
\text { is characterized by reduced psycho- } \\
\text { motor behavior and lethargy } \\
\text { - Mixed delirium } \\
\text { alternates unpredictably between a } \\
\text { hyperactive and a hypoactive } \\
\text { manifestation }\end{array}$ & $\begin{array}{l}\text { - Subsyndromal delirium } \\
\text { a condition in which patients } \\
\text { have one or more symptoms } \\
\text { that never progress to a full } \\
\text { diagnosis of delirium as } \\
\text { described by the DSM-IV-TR } \\
\text { criteria } \\
\text { - Delirium superimposed on } \\
\text { dementia } \\
\text { when delirium occurs in patients } \\
\text { with a pre-existing dementia }\end{array}$ \\
\hline
\end{tabular}

Fig. 1. Overview of the terminology of delirium.

\section{Delirium terminology and time course}

Delirium can be defined according to the time of presentation as prevalent, incident and persistent (Fig. 1). Delirium is defined as 'prevalent' when it is detected at the time of admission to a clinical setting. Conversely, delirium can be defined as 'incident' if it newly occurs during the course of a stay in a clinical setting. Finally, delirium can be named 'persistent' when delirium symptoms persist over the course of time. In the past, delirium was considered as a transitory syndrome. Several studies ${ }^{37-40}$ in non-ICU setting have shown that delirium symptoms can persist up to 1 month after the first diagnosis. ${ }^{41}$ Pisani et al., ${ }^{12}$ analysing the effect of delirium on mortality, reported the persistence of delirium up to 10 days after the first diagnosis in ICU patients.

\section{Motoric subtypes definition}

Delirium has been traditionally classified in non-ICU settings ${ }^{42-44}$ according to the psychomotor behaviour into subtypes as hyperactive, hypoactive delirium and mixed delirium ${ }^{42,45}$ (Fig. 1). 'Hyperactive delirium' is characterised by increased psycho-motor activity with agitated behaviour. 'Hypoactive' or 'quiet' 'delirium' is characterised by reduced psycho-motor behaviour and lethargy. Mixed delirium alternates unpredictably between a hyperactive and a hypoactive manifestation. In the ICU setting, the motoric subtypes of delirium have been defined with the use of the confusion assessment method for the ICU (CAM-ICU) ${ }^{4,6}$ along with the Richmond Agitation and Sedation Scale (RASS). ${ }^{46,47}$ The CAM-ICU is a screening tool for the detection of delirium in critically ill patients. The CAM-ICU presents a two-step approach. Level of consciousness (arousal) is first evaluated with the RASS, ${ }^{46,47}$ a 10-point scale ranging from -5 (no response to voice or physical evaluation) to +4 (overtly combative, violent and immediate danger for staff), with a score of 0 denoting a calm and alert patient. Patients who are comatose (RASS -5 or -4 ) cannot be assessed for delirium. Patients with a RASS score 
of -3 or greater $(-2$ to +4$)$ can be assessed by the CAM-ICU. The CAM-ICU comprises four features. To be diagnosed as delirious, one needs to have a RASS score of -3 or higher $(-2$ to +4$)$, with an acute change or fluctuation in mental status (Feature 1), accompanied by inattention (Feature 2), and either altered level of consciousness (Feature 3 ) or disorganised thinking (Feature 4). A patient is defined as having 'hyperactive delirium' if the CAM-ICU screening is positive for the presence of delirium and the RASS score is above 0; 'hypoactive delirium' is identified when the CAM-ICU screening is positive for delirium and the RASS score is between -1 and -3 . It is an interesting reporting that the prevalence of hypoactive delirium in critically ill patients ranges from $43.5 \%$ to $67 \%$, ${ }^{48-50}$ while the pure hyperactive and mixed ranges from $0 \%$ to $1.6 \%$, and from $6 \%$ to $54.9 \%$, respectively. ${ }^{48-50}$

\section{Additional definitions}

'Subsyndromal delirium (SSD)' is defined as a condition in which patients have one or more symptoms that never progress to a full diagnosis of delirium as described by the DSM-IV-TR criteria. For instance, a patient can have an acute change in mental status and disorganised thinking but does not show signs of inattention. It has been mainly described in non-ICU settings. ${ }^{51-54}$ Nonetheless, Ouimet and colleagues ${ }^{55}$ defined the presence of sub-syndromal delirium using the intensive care delirium checklist (ICDSC) in an ICU population. ${ }^{5}$ The ICDSC score ranges from 0 to 8 , with a score of 4 or higher indicating the presence of delirium. SSD was identified in 33.3\% of a cohort of ICU patients using an ICDSC cut-off score of 1-3. It has been showed that ICU patients who have sub-syndromal delirium experience worse outcomes than those who have no delirium at all, confirming previous reports ${ }^{51,54}$ of graded severity of brain dysfunction from normal to sub-syndromal to delirium.

Finally, when delirium is identified in patients with pre-existing dementia, it is named 'delirium superimposed on dementia (DSD). ${ }^{56}$ DSD has been specifically studied outside the ICU, and Fick and colleagues described a prevalence of DSD in a systematic review of the literature ranging from $50 \%$ to $89 \% .{ }^{57}$

\section{Cognitive impairment terminology}

ICU survivors often suffer significant long-term sequelae in the form of cognitive impairment. ${ }^{16}$ Though there has been an increasing interest on the LTCI-CI, it remains unclear how to best define it, as it is a less specific syndrome (as currently understood) than other diagnostic entities such as MCI, dementia and POCD. We report in detail the definitions, which have been used to describe these clinical entities trying to bring clarity to clinicians in their daily practise.

\section{Long-term cognitive impairment after a critical illness}

Jackson et al. ${ }^{58}$ have recently underlined that in the context of ICU survivors, two terms are often used in synonymous fashion - cognitive impairment and cognitive dysfunction; though it is unclear whether these terms always refer to the same clinical entity. In general, it may be more appropriate to use the term 'cognitive impairment' instead of 'cognitive dysfunction' given the fact that the neuropsychological changes found following a critical illness tend to persist and reflect deficits of a magnitude that are, indeed, functionally impairing.

The neurocognitive impairments of the patients with LTCI-CI are heterogeneous and most frequently involve memory, executive function and attention and are often similar to those experienced by individuals suffering from conditions such as a mild traumatic brain injury (MTBI) or MCI. ${ }^{25,59}$ These neurocognitive impairments represent a major burden for family and caregivers since they affect the abilities of ICU survivors to return to work, reduce life satisfaction and increased medical costs. ${ }^{31}$ To date, there is still a lack of consensus on how to define LTCI-CI especially in comparison to other forms of cognitive impairments, though broad agreement exists that a uniform definition would be helpful. ${ }^{60}$ Patients have been tested ${ }^{25}$ with neuropsychological batteries, which assess different cognitive domains: mental status, psychomotor speed, verbal fluency, working memory, verbal memory, visual memory and visuo-construction. Though definitions vary, they have tended to be quite restrictive (e.g., difficult to reach), as using such definitions ensure that subjects defined as 'impaired' are truly 
impaired and not false positives. One such definition (from a battery of nine tests) identifies impairment as either two neuropsychological test scores at least two standard deviation (S.D.) below the norm-referenced mean or three scores that are at least 1.5 S.D. below the norm-referenced mean. ${ }^{25}$

While definitions of impairment are sometimes developed by researchers and applied externally to test batteries (as described above), in other instances definitions of impairment or dysfunction are 'built into' existing neuropsychological batteries. Such is the case with the repeatable battery for the assessment of neuropsychological status (RBANS), ${ }^{61}$ a 'stand alone' tool for the evaluation of cognitive functioning widely employed in the assessment of elderly and medically ill patients, ${ }^{62,63}$ and as a 'stand alone' battery, it differs from those commonly used in research which often are comprised of individuals tests of specific domains culled from a range of sources. The RBANS generates 'index scores' based on subtest raw scores, which are interpreted based on the following classification system: 69 and below - extremely low, 70-79 - borderline, 80-89 - low average, 90-109 - average, 110-119 - high average, 120-129 - superior and 130 and above - very superior. The RBANS assesses immediate and delayed memory, attention and concentration, visual spatial construction and language. The tests and scoring system are described in Table 1.

An important question is whether LTCI-CI reflects patterns associated with neurodegenerative diseases such as Alzheimer's disease $(A D)^{64}$ or, alternatively, whether cognitive impairment after critical illness is static. The typical AD pattern at the beginning of the disease is characterised primarily though not exclusively by memory impairment and with cognitive deficits, which worsen progressively over time involving other cognitive domains (e.g., executive functions and language). By contrast, patients with LTCI-CI have diffuse neurocognitive deficits with a pattern, particularly among younger subjects, which appears to stabilise around 12-24 months after hospital discharge. ${ }^{59}$ As such, it appears that the cognitive impairment occurring in many ICU survivors is not neurodegenerative, though there may be substantial exceptions to this rule, including large numbers of individuals with mild subclinical decrements who transition more rapidly into dementia than would otherwise be the case. The majority of the studies evaluating LTCI-CI have excluded patients with pre-existing cognitive impairments. ${ }^{17,28,32,59}$ In the next sections, we report specific criteria for the diagnosis of MCI and dementia.

\section{MCI and dementia}

To provide a clear insight of the terminology of dementia, it is important to first define $\mathrm{MCI}$ and dementia, and then provide specific knowledge on the most common type of dementia (i.e.,AD).

$\mathrm{MCI}$ is 'generally used to refer to a transitional zone between normal cognitive function and clinically probable AD'. MCI is a clinical condition defined by the presence of the following criteria ${ }^{65-67}:(1)$ the person is neither normal nor demented (does not meet DSM-IV criteria for a dementia syndrome); (2) there is evidence of cognitive deterioration shown by either objectively measured decline over time and/or subjective report of decline by self and/or informant in conjunction with objective cognitive deficits; (3) the activities of daily living (i.e., taking medication, use of telephone, managing money, transportation, shopping and housework) are preserved, and complex instrumental functions are either intact or minimally impaired. $\mathrm{MCI}$ is further classified into four different subtypes according to specific neurocognitive deficits assessed through neuropsychological testing, though controversy exists about the stability of these more narrow constructs: (1) MCI amnestic: when only memory impairment is detected; (2) MCI multidomain amnestic: no memory impairment and multiple impairments in other neuropsychological domains (e.g., language and visuospatial); (3) MCI multidomain non-amnestic: more than one neuropsychological domain is impaired and the memory is normal; and (4) MCI single non-memory: one single neuropsychological domain is impaired and there is no memory impairment. Scores on cognitive tests for individuals with MCI are typically 1.5 S.D. below the mean for their age- and education-matched data, though $\mathrm{MCI}$ is a clinical diagnosis and no fixed cut-off criteria exist. A European longitudinal study reported an incidence rate per 1000 person years between 11.4 for amnestic MCI and 33.8 for other types of cognitive impairment no dementia. ${ }^{68} \mathrm{~A}$ $12 \%$ progression rate yearly from MCI to dementia is reported. ${ }^{69}$

Dementia criteria and specifically AD criteria have been recently updated. ${ }^{67,70}$ The prevalence of dementia increases dramatically with ageing. In fact, dementia affects $5-8 \%$ of individuals over the age of $65,15-20 \%$ over the age of 75 years and $25-50 \%$ of the individuals older than 85 years. AD represents 
Table 1

Definitions of cognitive impairments.

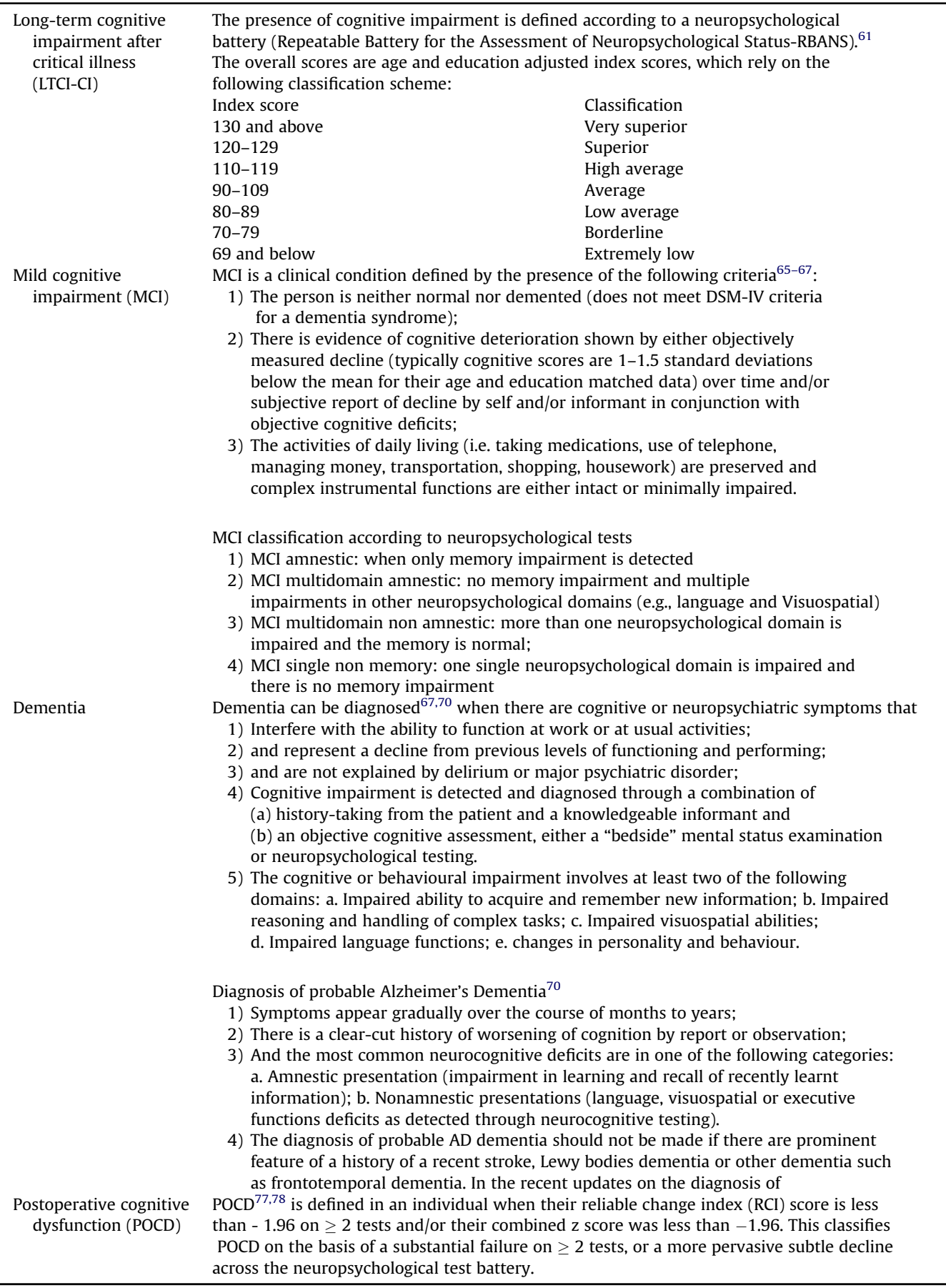


the most common type of dementia accounting for $50-75 \%$ of the cases of dementia. The last World Alzheimer Report estimated that there were 35.6 million people living with dementia worldwide in 2010 , increasing to 65.7 million by 2030 and 115.4 million by $2050 .^{71}$

The diagnosis of dementia is being revised and expanded. ${ }^{67,70}$ Presently, dementia can be diagnosed when there are cognitive or neuropsychiatric symptoms that (1) interfere with the ability to function at work or at usual activities; (2) represent a decline from previous levels of functioning and performing; (3) are not explained by delirium or major psychiatric disorder; (4) cognitive impairment is detected and diagnosed through a combination of (a) history taking from the patient and a knowledgeable informant and (b) an objective cognitive assessment, either a 'bedside' mental status examination or neuropsychological testing and (5) the cognitive or behavioural impairment involves at least two of the following domains: (a) impaired ability to acquire and remember new information; (b) impaired reasoning and handling of complex tasks; (c) impaired visuospatial abilities; (d) impaired language functions; and (e) changes in personality and behaviour.

Probable AD dementia is diagnosed when a patient meets criteria for dementia as described above and presents one of the following characteristics ${ }^{70}$ : (1) symptoms appear gradually over the course of months to years; (2) there is a clear-cut history of worsening of cognition by report or observation; and the most common neurocognitive deficits are in one of the following categories: (a) amnestic presentation (impairment in learning and recall of recently learnt information) and (b) non-amnestic presentations (language, visuospatial or executive functions deficits as detected through neurocognitive testing). The diagnosis of probable AD dementia should not be made if there are prominent features of a history of a recent stroke, Lewy bodies dementia or other dementia such as frontotemporal dementia. In the recent updates on the diagnosis of dementia, there have been thorough discussions on the role of biomarkers and neuroimaging. Nonetheless, in the context of this review, we report information mainly on terminology differences and therefore we refer the reader to the Recommendations of the National Institute on Ageing and the Alzheimer's Association workgroup ${ }^{70}$ for further details on the clinical and research use of these additional investigations.

\section{Postoperative cognitive dysfunction}

POCD is common and it has been studied after cardiac and non-cardiac surgery. It is reported in up to $30-65 \%$ of the patients at hospital discharge and $20-40 \%$ after few months of surgery, though questions exist related to the extent to which it represents a newly developed condition or whether it reflects a process of change that commonly occurs in individuals with cardiovascular disease, for example, even in the absence of surgery. ${ }^{72,73}$ The definition of POCD is variable and controversial and POCD should be differentiated from delirium. ${ }^{74}$ This distinction is possible through the use of neurocognitive tests. Several approaches have been taken to define POCD. ${ }^{74,75}$ Commonly used criteria include a $20 \%$ percentage change from a baseline evaluation in a pre-defined number of tests (usually two or more tests) or an absolute decline ( $>1$ S.D.) from baseline scores in two or more neuropsychological tests, though numerous other definitions have been employed as well. This approach, however, does not take into account the age-matched controls and, thus, the variability that could occur in healthy individuals over time. ${ }^{76} \mathrm{~A}$ more recent approach relies upon statistically driven methods to assess 'real change' through formulae such as the reliable change index (RCI). ${ }^{77,78}$ The RCI can be mathematically calculated using published methodology. ${ }^{77,78}$

\section{Summary}

ICU survivors often present acute and chronic cognitive co-morbidities in the form of delirium and long-term cognitive impairment (LTCI-CI), which are associated with adverse outcomes. Among health-care providers, delirium and LTCI-CI are often unrecognised.

The reason of this underdetection might be related to barriers in the terminology used to define these cognitive impairments. The use and knowledge of a correct terminology is a key factor to advance the management and to further develop research studies on these emergent health-care burdens in ICU survivors. 


\section{Practise points}

- Delirium is the most common form of acute brain dysfunction in critically ill patients and it is often underdetected.

- Delirium is an independent predictor of longer hospital stay, increased hospital cost, higher 6-month and 1-year mortality and long-term cognitive impairment.

- Long-term cognitive impairment occurs in at least 5 out of 10 patients at 1 year after an acute critical illness and its presence is often underestimated.

- The reason for underdetection for acute and long-term brain dysfunction might indeed be related to barriers in the terminology used in these clinical entities.

\section{Research agenda}

- Further research is warranted to increase the knowledge of delirium and long-term cognitive impairment following a critical illness.

- Future research should provide a specific definition of LTCI-CI to differentiate from other forms of cognitive impairment such as MCI, AD and POCD.

- The clinical definition of the trajectories of LTCI-CI would allow to design protocols for the prevention and treatment of this increasing health-care burden.

\section{Funding/support}

Dr. Pandharipande is supported by the VA Clinical Science Research and Development Service (VA Career Development Award). Dr. Ely is supported by the VA Clinical Science Research and Development Service (VA Merit Review Award) and the National Institutes of Health (AG027472). Dr Bellelli has received honoraria from Novartis, Pfizer, Lilly and Lundbeck.

\section{Potential conflict of interest}

Dr. Pandharipande has received honoraria from Hospira, Inc and Orion Pharma. Dr. Ely has received honoraria from GSK, Pfizer, Lilly, Hospira and Aspect. All the other authors report no financial conflict of interest.

\section{References}

1. Adhikari NK, Fowler RA, Bhagwanjee S et al. Critical care and the global burden of critical illness in adults. Lancet 2010; 376: $1339-1346$.

2. Cheung AM, Tansey CM, Tomlinson G et al. Two-year outcomes, health care use, and costs of survivors of acute respiratory distress syndrome. Am J Respir Crit Care Med 2006; 174: 538-544.

3. Angus D, Musthafa AA, Clermonte $G$ et al. Quality-adjusted survival in the first year after the acute respiratory distress syndrome. Am J Respir Crit Care Med 2001; 163: 1389-1394.

*4. Ely EW, Inouye SK, Bernard GR et al. Delirium in mechanically ventilated patients: validity and reliability of the confusion assessment method for the intensive care unit (CAM-ICU). JAMA 2001; 286: 2703-2710.

5. Bergeron N, Dubois MJ, Dumont M et al. Intensive care delirium screening Checklist: evaluation of a new screening tool. Intensive Care Med 2001; 27: 859-864.

6. Ely EW, Margolin R, Francis J et al. Evaluation of delirium in critically ill patients: validation of the confusion assessment method for the intensive care unit (CAM-ICU). Crit Care Med 2001; 29: 1370-1379.

*7. Dubois MJ, Bergeron N, Dumont M et al. Delirium in an intensive care unit: a study of risk factors. Intensive Care Med 2001; 27: 1297-1304.

8. Ely EW, Gautam S, Margolin R et al. The impact of delirium in the intensive care unit on hospital length of stay. Intensive Care Med 2001; 27: 1892-1900.

9. Ouimet S, Kavanagh BP, Gottfried SB et al. Incidence, risk factors and consequences of ICU delirium. Intensive Care Med 2007; 33: 66-73. 
10. Thomason JW, Shintani A, Peterson JF et al. Intensive care unit delirium is an independent predictor of longer hospital stay: a prospective analysis of 261 non-ventilated patients. Crit Care 2005; 9: R375-R381.

11. Milbrandt EB, Deppen S, Harrison PL et al. Costs associated with delirium in mechanically ventilated patients. Crit Care Med 2004; 32: 955-962.

12. Pisani MA, Kong SY, Kasl SV et al. Days of delirium are associated with 1-year mortality in an older intensive care unit population. Am J Respir Crit Care Med 2009; 180: 1092-1097.

13. Ely EW, Shintani A, Truman B et al. Delirium as a predictor of mortality in mechanically ventilated patients in the intensive care unit. JAMA 2004; 291: 1753-1762.

14. Lin SM, Liu CY, Wang CH et al. The impact of delirium on the survival of mechanically ventilated patients. Crit Care Med 2004; 32: 2254-2259.

15. McNicoll L, Pisani MA \& Inouye SK. One-year outcomes following delirium in older ICU patients [abstract]McNicoll L, Pisani MA, Inouye SK. J Am Geriatr Soc 2004; 52: S2.

16. Hopkins RO \& Jackson JC. Short- and long-term cognitive outcomes in intensive care unit survivors. Clin Chest Med 2009; 30: $143-153$. ix.

*17. Jackson JC, Gordon SM, Hart RP et al. The association between delirium and cognitive decline: a review of the empirical literature. Neuropsychol Rev 2004; 14: 87-98.

18. Jackson JC, Gordon SM, Girard TD et al. Delirium as a risk factor for long term cognitive impairment in mechanically ventilated ICU survivors [abstract]Jackson JC, Gordon SM, Girard TD, et al. Am J Respir Crit Care Med 2007; 175: A22.

*19. Maclullich AM, Beaglehole A, Hall RJ et al. Delirium and long-term cognitive impairment. Int Rev Psychiatry 2009; 21: $30-42$.

20. van den Boogaard M, Schoonhoven L, van der Hoeven JG et al. Incidence and short-term consequences of delirium in critically ill patients: a prospective observational cohort study. Int J Nurs Stud 2011.

21. Jones C, Griffiths RD, Slater T et al. Significant cognitive dysfunction in non-delirious patients identified during and persisting following critical illness. Intensive Care Med 2006; 32: 923-926.

22. Girard TD, Jackson JC, Pandharipande PP et al. Delirium as a predictor of long-term cognitive impairment in survivors of critical illness. Crit Care Med 2010; 38: 1513-1520.

23. Jackson JC, Girard TD, Gordon SM et al. Long-term cognitive and psychological outcomes in the awakening and breathing controlled trial. Am J Respir Crit Care Med 2010; 182: 183-191.

24. Jackson JC, Gordon SM, Burger D et al. Acute respiratory distress syndrome and long term cognitive impairment: a case study. Arch Clin Neuropsychol 2003; 18: 688.

25. Jackson JC, Hart RP, Gordon SM et al. Six-month neuropsychological outcome of medical intensive care unit patients. Crit Care Med 2003; 31: 1226-1234.

26. Sukantarat KT, Burgess PW, Williamson RC et al. Prolonged cognitive dysfunction in survivors of critical illness. Anaesthesia 2005; 60: 847-853.

27. Al-Saidi F, McAndrews MP, Cheung AM et al. Neuropsychological sequelae in ARDS survivors [abstract]Al-Saidi F, McAndrews MP, Cheung AM, et al. Am J Respir Crit Care Med 2003; 167: A737.

*28. Hopkins RO, Weaver LK, Pope D et al. Neuropsychological sequelae and impaired health status in survivors of severe acute respiratory distress syndrome. Am J Respir Crit Care Med 1999; 160: 50-56.

29. Hopkins RO, Weaver LK, Chan KJ et al. Quality of life, emotional, and cognitive function following acute respiratory distress syndrome. J Int Neuropsychol Soc 2004; 10: 1005-1017.

30. Hopkins RO, Weaver LK, Collingridge D et al. Two-year cognitive, emotional, and quality-of-life outcomes in acute respiratory distress syndrome. Am J Respir Crit Care Med 2005; 171: 340-347.

31. Rothenhausler HB, Ehrentraut S, Stoll C et al. The relationship between cognitive performance and employment and health status in long-term survivors of the acute respiratory distress syndrome: results of an exploratory study. Gen Hosp Psychiatry 2001; 23: 90-96.

32. Suchyta MR, Hopkins RO, White J et al. The incidence of cognitive dysfunction after ARDS. [abstract]Suchyta MR, Hopkins RO, White J, Jephson A, Morris AH. Am J Respir Crit Care Med 2004; 169: A18.

33. Morandi A, Pandharipande P, Trabucchi M et al. Understanding international differences in terminology for delirium and other types of acute brain dysfunction in critically ill patients. Intensive Care Med 2008; 34: 1907-1915.

34. American Psychiatric Association. Diagnostic and statistical manual of mental disorders. text revision. 4th edition. Washington, DC: American Psychiatric Association, 2000.

35. Salluh JI, Dal-Pizzol F, Mello PV et al. Delirium recognition and sedation practises in critically ill patients: a survey on the attitudes of 1015 Brazilian critical care physicians. J Crit Care 2009.

36. Lipowski ZJ. Delirium, clouding of consciousness and confusion. J Nerv Ment Dis 1967; 145: 227-255.

37. O'Keeffe ST \& Lavan JN. Clinical significance of delirium subtypes in older people. Age Ageing 1999; 28: 115-119.

38. O'Keeffe S \& Lavan J. The prognostic significance of delirium in older hospital patients. J Am Geriatr Soc 1997; 45: 174-178.

39. Manos PJ \& Wu R. The duration of delirium in medical and postoperative patients referred for psychiatric consultation. Ann Clin Psychiatry 1997; 9: 219-226.

40. Levkoff SE, Evans DA, Liptzin B et al. Delirium. the occurrence and persistence of symptoms among elderly hospitalized patients. Arch Intern Med 1992; 152: 334-340.

41. Kiely DK, Bergmann MA, Murphy KM et al. Delirium among newly admitted postactue facility patients: prevalence, symptoms, and severity. Gerontol A Biol Sci Med Sci 2003; 58: M441-M445.

42. Lipowski ZJ. Delirium in the elderly patient. N Engl J Med 1989; 320: 578-582.

43. Lipowski ZJ. Delirium: acute confusional states. Rev. ed. New York: Oxford University Press, 1990.

*44. Meagher DJ \& Trzepacz PT. Motoric subtypes of delirium. Semin Clin Neuropsychiatry 2000; 5: 75-85.

45. Liptzin B \& Levkoff SE. An empirical study of delirium subtypes. Br J Psychiatry 1992; 161: 843-845.

46. Ely EW, Truman B, Shintani A et al. Monitoring sedation status over time in ICU patients: reliability and validity of the Richmond Agitation-Sedation Scale (RASS). JAMA 2003; 289: 2983-2991.

47. Sessler CN, Gosnell MS, Grap MJ et al. The Richmond Agitation-Sedation Scale: validity and reliability in adult intensive care unit patients. Am J Respir Crit Care Med 2002; 166: 1338-1344. 
48. Pandharipande P, Cotton BA, Shintani A et al. Motoric subtypes of delirium in mechanically ventilated surgical and trauma intensive care unit patients. Intensive Care Med 2007; 33: 1726-1731.

49. Robinson TN, Raeburn CD, Tran ZV et al. Motor subtypes of postoperative delirium in older adults. Arch Surg 2011; 146: 295-300.

50. Peterson JF, Pun BT, Dittus RS et al. Delirium and its motoric subtypes: a study of 614 critically ill patients. J Am Geriatr Soc 2006; 54: 479-484.

51. Cole M, McCusker J, Dendukuri N et al. The prognostic significance of subsyndromal delirium in elderly medical inpatients. J Am Geriatr Soc 2003; 51: 754-760.

52. Levkoff SE, Liptzin B, Cleary PD et al. Subsyndromal delirium. Am J Geriatr Psychiatry 1996; 4: 320-329.

53. Levkoff SE, Yang FM \& Liptzin B. Delirium: the importance of subsyndromal states. Prim Psychiatry 2004; 11: 40-44.

54. Marcantonio ER, Ta T, Duthrie E et al. Delirium severity and psychomotor types: their relationship with outcomes after hip fracture repair. J Am Geriatr Soc 2002; 50: 850-857.

55. Ouimet S, Riker R, Bergeon N et al. Subsyndromal delirium in the ICU: evidence for a disease spectrum. Intensive Care Med 2007; 33: 1007-1013.

56. Fick DM, Kolanowski AM, Waller JL et al. Delirium superimposed on dementia in a community-dwelling managed care population: a 3-year retrospective study of occurrence, costs, and utilization. J Gerontol A Biol Sci Med Sci 2005; 60: 748-753.

57. Fick DM, Agostini JV \& Inouye SK. Delirium superimposed on dementia: a systematic review. J Am Geriatr Soc 2002; 50: 1723-1732.

58. Jackson JC, Mitchell N \& Hopkins RO. Cognitive functioning, mental health, and quality of life in ICU survivors: an overview. Anesthesiol Clin 2011; 29: 751-764.

59. Hopkins RO \& Jackson JC. Long-term neurocognitive function after critical illness. Chest 2006; 130: 869-878.

60. Jackson JC, Gordon SM, Ely EW et al. Research issues in the evaluation of cognitive impairment in intensive care unit survivors. Intensive Care Med 2004; 30: 2009-2016.

61. Randolph C. Repeatable battery for the assessment of neuropsychological status (RBANS) manual. San Antonio: Psychological Corporation, 1998.

62. Benitez A, Horner MD \& Bachman D. Intact cognition in depressed elderly veterans providing adequate effort. Arch Clin Neuropsychol 2011; 26: 184-193.

63. Landgraff NC, Whitney SL, Rubinstein EN et al. Cognitive and physical performance in patients with asymptomatic carotid artery disease. J Neurol 2010; 257: 982-991.

64. Hopkins RO, Ely EW \& Jackson JC. The role of future longitudinal studies in ICU survivors: understanding determinants and pathophysiology of brain dysfunction. Curr Opin Crit Care 2007; 13: 497-502.

65. Winblad B, Palmer K, Kivipelto M et al. Mild cognitive impairment-beyond controversies, towards a consensus: report of the international working group on mild cognitive impairment. J Intern Med 2004; 256: 240-246.

*66. Petersen RC. Mild cognitive impairment as a diagnostic entity. J Intern Med 2004; 256: 183-194.

67. Albert MS, DeKosky ST, Dickson D et al. The diagnosis of mild cognitive impairment due to Alzheimer's disease: recommendations from the National Institute on Aging-Alzheimer's Association Workgroups on diagnostic guidelines for Alzheimer's disease. Alzheimers Dement 2011; 7: 270-279.

68. Caracciolo B, Palmer K, Monastero R et al. Occurrence of cognitive impairment and dementia in the community: a 9-yearlong prospective study. Neurology 2008; 70: 1778-1785.

69. Petersen RC \& Morris JC. Clinical features. mild cognitive impairment: aging to Alzheimer's disease. New York: Oxford University Press, Inc, 2003. 15-40.

*70. McKhann GM, Knopman DS, Chertkow $\mathrm{H}$ et al. The diagnosis of dementia due to Alzheimer's disease: recommendations from the National Institute on Aging-Alzheimer's Association Workgroups on diagnostic guidelines for Alzheimer's disease. Alzheimers Dement 2011; 7: 263-269.

71. Alzheimer's Disease International World Alzheimer Report 2010 The Global Economic Impact of Dementia. 2010.

72. Newman MF, Kirchner JL, Phillips-Bute B et al. Longitudinal assessment of neurocognitive function after coronary-artery bypass surgery. N Engl J Med 2001; 344: 395-402.

73. Knipp SC, Matatko N, Wilhelm H et al. Cognitive outcomes three years after coronary artery bypass surgery: relation to diffusion-weighted magnetic resonance imaging. Ann Thorac Surg 2008; 85: 872-879.

74. Bodolea C, Hagau N, Coman I et al. Postoperative cognitive dysfunction in elderly patients. an integrated psychological and medical approach. J Cogn Behaviour Psychotherapy 2008; 8: 117-132.

75. van Harten AE, Scheeren TW \& Absalom AR. A review of postoperative cognitive dysfunction and neuroinflammation associated with cardiac surgery and anaesthesia. Anaesthesia 2012; 67: 280-293.

76. Mahanna EP, Blumenthal JA, White WD et al. Defining neuropsychological dysfunction after coronary artery bypass grafting. Ann Thorac Surgery 1996; 61: 1342-1347.

*77. Rasmussen LS, Larsen K, Houx P et al. The assessment of postoperative cognitive function. Acta Anaesthesiol Scand 2001; 45: $275-289$.

78. Evered L, Scott DA, Silbert B et al. Postoperative cognitive dysfunction is independent of type of surgery and anesthetic. Anesth Analg 2011; 112: 1179-1185. 